\title{
The Impact of Productive Safety Net Program on the Household Food Security: The Case of Kutaber District
}

\author{
Andualem Kassegn Amede \\ Department of Agricultural Economics, College of Agriculture, Woldia University, Woldia, Ethiopia \\ Email address: \\ andualemkassegn@gmail.com

\section{To cite this article:} \\ Andualem Kassegn Amede. The Impact of Productive Safety Net Program on the Household Food Security: The Case of Kutaber District. \\ European Business \& Management. Vol. 6, No. 1, 2020, pp. 10-19. doi: 10.11648/j.ebm.20200601.12
}

Received: March 24, 2020; Accepted: April 10, 2020; Published: May 12, 2020

\begin{abstract}
The Ethiopian government launched a new social protection program called the Productive Safety Net Program since Poverty and chronic food insecurity have been the main challenges for most of the rural households of the country. The major objective of this study was to examine the impact of PSNP on household food security. The study was conducted in Kutaber district, Amhara National regional state, Ethiopia. A Multistage stage sampling procedure was used to randomly select 116 representative household heads. Both the primary and secondary data were analyzed using descriptive statistics and econometric tools. The propensity score matching (PSM) technique of impact evaluation preferred to overcome the counterfactual problem and selection bias. Participation model result of Estimated Propensity Score showed that among 11 explanatory variables included in the logistic model, 4 of them were significant. The result indicated that the program participation of the households in the area significantly influenced by farmland size, an income of off/non-farm activities, distance to the nearest market center and distance to the nearest agricultural extension office. The program intervention has resulted in a positive and statically significant mean difference between the two groups in terms of the outcomes variables of daily calorie intake and farm and household material. Applying a propensity score matching technique for the study found that the program has increased participating households' calorie intake and household material by 233.04 calories and 2551.65 ETB, respectively compared to that of non-participating households. The analysis result revealed that the food security of the household has been improved by productive safety net program intervention in the study area. The multiple linear regression model estimated results revealed that the impact of the program on calorie intake was not uniform across the participating households. Therefore, the program should consider the roles of significant variables in the selection of participant households for the desired impact under related locations.
\end{abstract}

Keywords: Food Security, Intervention, Impact, Porosity Score Matching, Kutaber

\section{Introduction}

Ethiopia is one of the most food-insecure and famine affected country. A large portion of the country's population has been affected by chronic and transitory food insecurity [2]. The food security situation in Ethiopia is highly linked to recurring food shortages and famine, which are associated with recurrent drought. According to [10], mainly seven factors affect household food security in Ethiopia. These are the technology used, farming systems, farm size, soil quality, family size, aggregated per capita production, and access to markets. Environmental degradation is also a critical factor that exacerbates soil loss, deforestation, and pest incidence, all of which affect food security. Besides, rapid population growth, poverty, rural-urban migration, and conflict can contribute to food insecurity. The increasing population growth in rural Ethiopia obliged households to cultivate and make their living on the extremely small size of land. For instance, $29 \%$ of grain farmers in 2006/7 had cultivated a land less than 0.5 ha per household [7]. According to recent FDRE [9] evidence, nearly 55 percent of all smallholder farmers operate on one hectare or less. Due to the smaller farm size and low return from farming activities, the majority of rural households are exposed to food insecurity and chronic poverty. Ethiopia has struggled for many years to respond to the challenges of food insecurity and rural poverty arising from many 
adverse factors [9].

Despite the decline in chronic poverty and chronic food insecurity, they are still the major challenges of policymakers and citizens at large. According to FAO [8] more than 41 percent of Ethiopian's live below the poverty line and above 31 million people are undernourished. Using the threshold of 2,550 kilocalories (Kcal) per adult equivalent per day, 40 percent of Ethiopian households mostly residing in rural parts of the country were food insecure and undernourished [22]. Moreover, the national survey conducted in $2003 / 4$ by EEA indicated that 63 percent of surveyed households were food deficit in Ethiopia. This evidence is supported by FAO [8] in that about 61 percent of people were undernourished in Ethiopia. Because most of the chronically food-insecure households are engaged in subsistence farming on small fragmented plots of degraded land, their livelihood increasing subject to weather fluctuations as a result of climate change._Climatic factors and natural resource availability are critical factors of food security in Ethiopia, where more than $80 \%$ of the population makes a living from agriculture $[1,6]$.

In Ethiopia, the seriousness of the food shortage problem varies from one area to another, depending on the state of the natural resources and the extent of development of food shortage [20]. The problem of food insecurity in Ethiopia has, to a large extent, been addressed by annual emergency food aid from abroad. During the past two decades, Ethiopia has been the largest recipient of food aid in Africa and one of the largest recipients in the world [8]. In 2003, the Government launched a major consultation process with development partners that aimed to formulate an alternative to crisis response to support the needs of chronically food-insecure households, as well as to develop long-term solutions to the problem of food insecurity. This culminated in the New Coalition for Food Security that proposed a Food Security Program (FSP) aimed at shifting households out of the emergency relief system while also enabling them to 'graduate' to sustainable food security. In 2005, to combat the persistent problem of food insecurity and to move away from the previous system of annual emergency appeals, the Ethiopian government and a consortium of donors (including the World Bank, U.S. Agency for International Development, Canadian International Development Agency, and several European donors) launched a new social protection program called the Productive Safety Net Program (PSNP). This program was a new initiative for reducing poverty in general and combating hunger and vulnerability in particular [19]. Its objective is to provide food/or cash transfers to chronically food-insecure households in a way that prevents asset depletion at the household level and generates productive assets at the community level [3]. It represents a serious and innovative attempt on the part of the Government of Ethiopia to move away from responding to chronic hunger through emergency appeals towards a more predictable resource for the predictable problems [19]. With an annual budget of nearly $\$ 500$ million, it is a huge program, reaching more than 7 million Ethiopians [11]. The PSNP is one of the major components of the food security program implemented by the Ethiopian government with the joint support of donors that aimed at providing more reliable and timely support to chronically food-insecure households.

PSNP delivers timely, predictable and appropriate transfers to assist chronically food-insecure households. Because it is launched to assure food consumptions and prevents assets depletion for food-insecure households in chronically foodinsecure districts. Despite the program stimulating markets, improving access to services and rehabilitating and enhancing the natural resources and environment, household food security of the rural household is not improved as expected since household food security largely depends on external factors including rainfall patterns, land degradation, climate change, population density, low levels of rural investment and the global market [21].

However, PSNP provides a safety net for chronically food-insecure households and also non-chronic households affected by shocks through the public works infrastructure built; it contributes to a local enabling environment for community development. This helps chronic households to rise from the platform provided by the safety net and helps households to move towards full food security. In Ethiopia, households who are often exposed to food insecurity due to different factors have participated in the program. More than one-third of its rural districts are now characterized by risky environments exposed to protracted food crises [12]. Currently, in the Amhara region, there are 64 chronically food incurred districts and all of which are supported by a productive safety net program. Kutaber district is one of the chronically food insecure and vulnerable districts of the South Wollo zone, in East Amhara Region.

Some limited empirical studies have been worked by different researchers to assess the impact of PSNP on household food security in Ethiopia by using crosssectional data [5]. Ethiopia's Safety Net is found to have positively impacted food insecure households in diverse ways $[14,15]$. Even though several attempts have been made to examine the impact of PSNP countrywide, there is limited empirical evidence on whether or not the program efforts have an impact on program participants' food security at the district level. In the district, the was no empirical works concerning the impact of the productive safety net program of the household food security status in the study area. Therefore, the objective of the research is to examine the impacts of a productive safety net program on the household food security status in the Kutaber district. Thus, this study attempts to fill this research gap and empirically investigate and pronounce the impact of the program on household food security. 


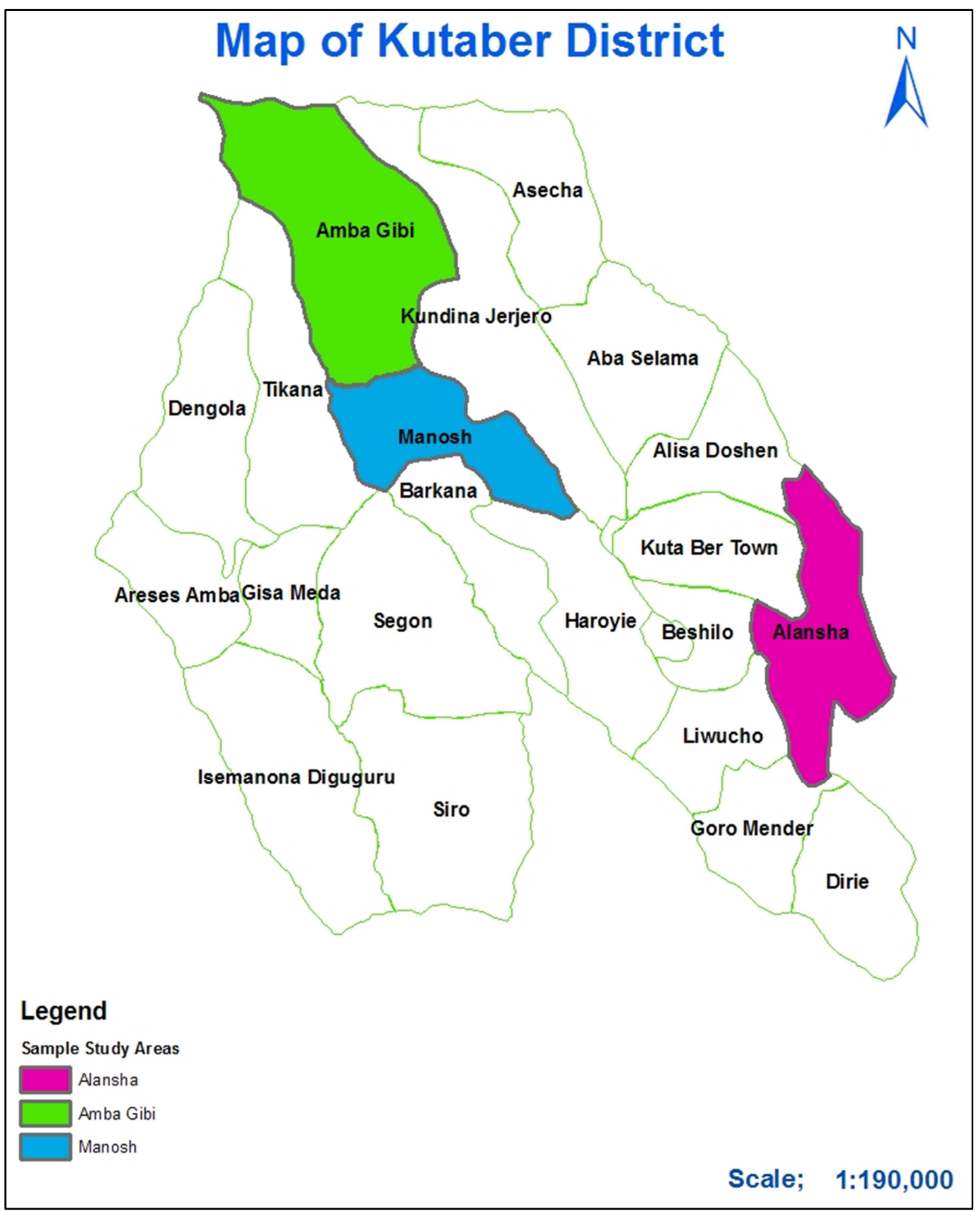

Figure 1. The map of kutaber district.

\section{Research Methodology}

\subsection{Description of the Study Area}

This study was conducted at Kutaber district. The district is located at about $421 \mathrm{~km}$ from Addis Abeba. It is one of the 23 rural districts in south wollo zone, Amhara National Regional State with a total area of 70071 ha The district is divided into 20 rural kebeles and one urban kebele. It has a total population size of 5842 and 96039 who live in an urban and rural area, respectively [17]. It is bordered by
Tehulederie in the east, Tenta in the west, Ambassel in the north and Dessie Zuriya districts in the south. Its geographical location is explained by $20 \%$ mountains, $10 \%$ plateau, $9 \%$ valley and $59 \%$ undulating [16]. That means the climate is ( $41 \%$ Dega, $55 \%$ woyna dega and $4 \%$ kolla). The total rainfall is estimated from the range between $500 \mathrm{~mm}$ to $995 \mathrm{~mm}$. The annual mean temperature of the district is $16^{\circ} \mathrm{C}$. The district is categorized into bi-modal rain falls, i.e., belg (ranges from February to April) and kiremt (Main rainy season extends from June to September).

In the study area, barley, wheat, teff, maize, Sorghum and bean are the major annual produce crops grown by the 
majority of the farmers in almost all kebelles. In addition to annual crops chat, potato, coffee, and fruits like apples, plum, pears, avocado, papaya, and banana are grown by some innovative farmers by using pond lined and small irrigation for home consumption and cash sources. The district is greatly known by the plantation of the Eucalyptus tree. It is intensively grown for house construction, fuel sources, fencing, land management, commercial purpose, and risk management, and currently, this tree is the main source of income of the farmers.

Livestock is the other major component of the farming system in the district. The mainly rearing livestock are sheep, goat, hen, asses and cattle ox (bulls), cows, heifer, calves, mules, and horses are commonly reared by almost by all farmers. Moreover, some farmers practice modern and traditional beekeeping.

\subsection{Sampling Techniques}

A multistage sampling technique was used to select the sample households. Kutaber district is selected purposively based on its high food insecurity problem in the region. In the second stage, from a total of 20 kebeles where the PSNP has been operating, three representative kebeles were selected randomly. In this study, at the final stage, 116 household heads both from participants and non-participants of the program were selected by using a random sampling technique proportional to the number of households from the sampling kebelles. The appropriate sample size was determined by both participants and non-participants by using the simplified formula of [23].

$$
n=\frac{N}{1+N(e)^{2}}
$$

Where,

$n=$ Sample size, $N=$ Size of population, and $\mathrm{e}=$ margin error

\subsection{Sources and Methods of Data Collection}

Both primary and secondary sources were used for the study. The primary data in this study were collected using semi-structured questionnaires that were pre-tested for validity and reliability. Moreover, primary data will be collected through FGD and key informant interviews to complement the research with qualitative information. Relevant data were collected from secondary sources to supplement primary information. The secondary sources from different published and unpublished documents were collected.

\subsection{Methods of Data Analysis}

The empirical data were analyzed using both descriptive and inferential statistical tools. Descriptive statistics which include mean, standard error, percentages, graphs and tables; and inferential statistics such as t-test and chi-square tests were applied for analyzing data for this study. The study applied a PSM technique, which is a widely applied impact evaluation instrument in the absence of baseline survey data for impact evaluation. STATA software was employed for the analysis of the data.

\subsubsection{Propensity Score Matching (PSM) Model}

The PSM technique enables us to extract from the sample of non-participating households a set of matching households that look like the participating households in all relevant preintervention characteristics. The study attempted to estimate the average impact of treatment on treated (ATT). In the study "treatment" implies participation in the program, which is a Productive Safety Net Program, and "impact" is meant for the change of food security status of households as an outcome indicator. Propensity score matching is often used in a program evaluation setting, where the objective is to compare participant outcomes with and without treatment.

The households are then divided into two groups, those who are treated by the program and those who do not and ranked according to their propensity score. Finally, the households are matched with similar households from the other group. In this way, households in the treatment group can be matched and compared with households from the control group who have similar characteristics in every aspect except that they don't treated by the program.

In equation form, the potential outcomes are then defined as:

$Y i(D i)$ for each individual $\mathrm{i}$, where $i 1,2, \ldots \ldots,=$, then the treatment effect of individual i can be expressed as;

$$
T_{i}=Y_{i(1)-} Y_{i(0)}
$$

Where $Y_{i 1}$ and $Y_{i 0}$ is the outcome with and without treatment respectively for household $i$. Consider $D=$ $\{0,1\}$ to be a binary indicator where 1 equal being assigned into treatment and 0 means not being assigned treatment. The Average Treatment Effect on the Treated (ATT), defined by:

$$
\mathrm{ATT}=\mathrm{E}\left[\frac{\mathrm{Y}^{1}}{\mathrm{D}}=1\right]-\mathrm{E}\left(\mathrm{Y}^{0} / \mathrm{D}=1\right]
$$

Where $E\left[Y^{1} / D=1\right]$ is never observed. Replacing $\mathrm{E}\left[\mathrm{Y}^{0} / \mathrm{D}=1\right]$ by the expected value of $\left(\mathrm{Y}^{0} / \mathrm{D}=1\right]$, which is observable in ATE, would not give an accurate estimate as long as

$Y^{0}$ for the treated and comparison group systematically differs. The true parameter is only identified if:

$$
\mathrm{ATT}=\mathrm{E}\left[\frac{\mathrm{Y}^{0}}{\mathrm{D}}=1\right]-\mathrm{E}\left(\mathrm{Y}^{0} / \mathrm{D}=0\right]
$$

As discussed above, this is not very likely to hold in nonexperimental studies. Instead, it relies on a matching approach to derive a counterfactual that enables us to match treated households with non-treated households with similar characteristics as possible to reduce the bias from selfselection. The matching is made based on an index, the propensity score, summarizing the pre-treatment characteristics of each household. The propensity score is the probability of assignment into treatment, $p(x)$, conditional on a set of pre-treatment characteristics, $X$, so that 


$$
p(x)=\operatorname{Pr}[D=1 / X]=E[D / X]
$$

Table 1. Type, definition, measurement, and hypothesis of variables used in PSM analysis.

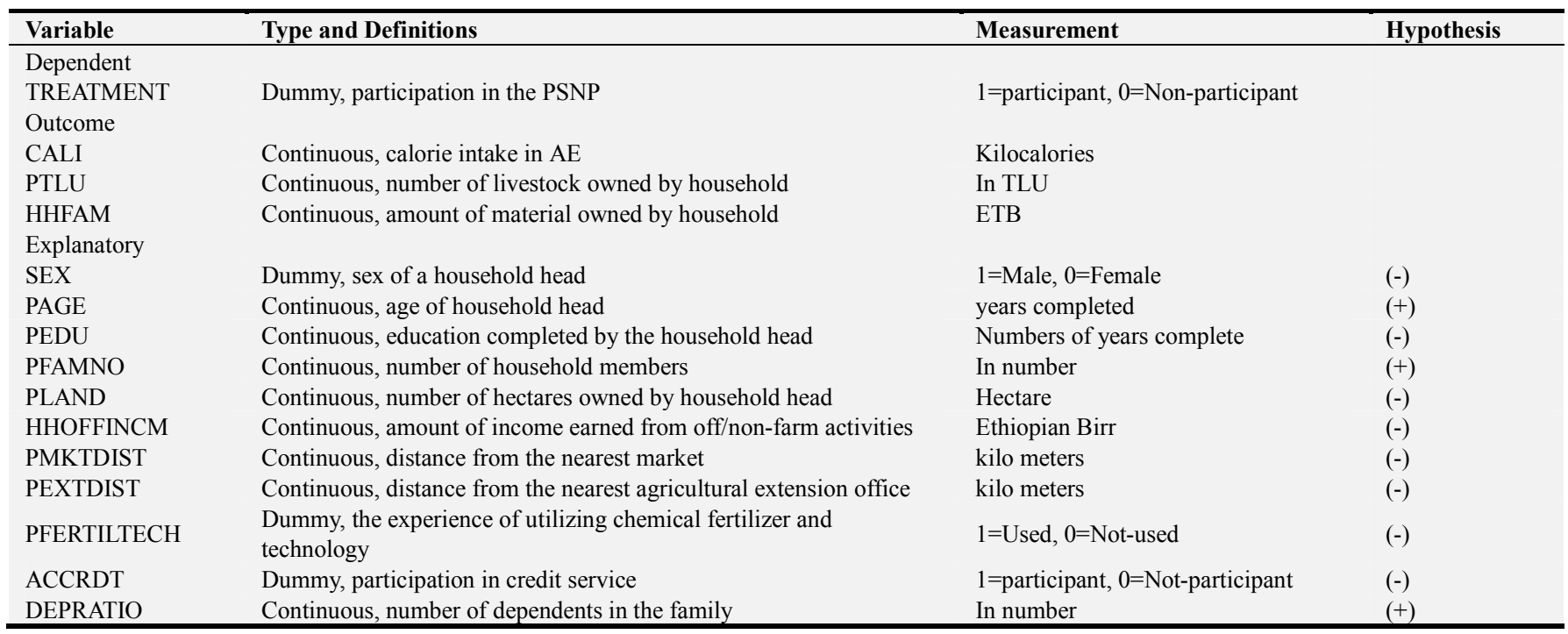

\section{Results and Discussion}

The study employed primary data collected from 116 households of three Kebeles of the district. Table 2 and Table 3 presents descriptive statistics of sample households for continuous and discrete variables.

\subsection{Descriptive Results of Pre-treatment Characteristics}

Both continuous and discrete variables were used in order to describe the sample households included in this study.

Table 2. Descriptive statistics of sample households (for continuous variables).

\begin{tabular}{|c|c|c|c|c|c|c|c|}
\hline \multirow{2}{*}{ Variable } & \multicolumn{2}{|c|}{ Treatment $(\mathrm{N}=48)$} & \multicolumn{2}{|c|}{ Control $(N=68)$} & \multicolumn{2}{|c|}{ Total $(\mathrm{N}=116)$} & \multirow{2}{*}{ t-value } \\
\hline & Mean & Std. err & Mean & Std. err & Mean & Std. err & \\
\hline PAGE & 47.64 & 1.56 & 46.91 & 1.49 & 47.22 & 1.08 & 0.111 \\
\hline PEDU & 0.79 & 0.08 & 1.03 & 0.09 & 0.93 & 0.07 & 2.93 \\
\hline PFAMNO & 4.26 & 0.23 & 4.64 & 0.23 & 4.42 & 0.16 & 0.256 \\
\hline PLAND & 0.33 & 0.04 & 0.63 & 0.05 & 0.50 & 0.03 & $-6.74 * * *$ \\
\hline HHOFFINCM & 193.13 & 81.08 & 2032.3 & 243.04 & 1271.3 & 168.59 & $-4.02 * * *$ \\
\hline PMKTDIST & 2.27 & 0.20 & 4.06 & 0.26 & 3.32 & 0.19 & $-4.22 * * *$ \\
\hline DEPRATIO & 0.93 & 0.09 & 0.66 & 0.07 & 0.77 & 0.06 & $3.93 * * *$ \\
\hline
\end{tabular}

*** show level of significance at $1 \%$.

Source: Own survey result (2014).

As shown in Table 2, the statistical analysis for this study revealed that there is a significant difference between program participants and non-participants in terms of their number of hectare owned by the household head, amount of income earned from off/non-farm activities, distance from the nearest market, distance from nearest agricultural extension office and number of dependents in the family. But the study result showed an insignificant difference between the two groups in terms of the sex of a household head, level of education completed by a household head and several households.

Table 3. Descriptive statistics of sample households (for discrete variables).

\begin{tabular}{|c|c|c|c|c|c|c|c|c|}
\hline \multirow{2}{*}{ Variables } & \multirow{2}{*}{ Category } & \multicolumn{2}{|c|}{ Participant } & \multicolumn{2}{|c|}{ Non-participant } & \multicolumn{2}{|c|}{ Total } & \multirow{2}{*}{$\begin{array}{l}\text { Chi-square Tes } \\
\chi^{2} \text {-value }\end{array}$} \\
\hline & & No. & $\%$ & No. & $\%$ & No. & $\%$ & \\
\hline \multirow{2}{*}{ SEX } & Male & 33 & 68.75 & 52 & 76.47 & 85 & 73.28 & \multirow{2}{*}{0.237} \\
\hline & Female & 15 & 31.25 & 16 & 23.53 & 31 & 26.72 & \\
\hline \multirow{2}{*}{ PFERTILTECH } & Household not-used & 31 & 64.58 & 50 & 73.53 & 81 & 69.83 & \multirow{2}{*}{0.203} \\
\hline & Household used & 17 & 35.42 & 18 & 26.47 & 35 & 30.17 & \\
\hline \multirow{2}{*}{ ACCRDT } & Not- participated & 19 & 39.58 & 21 & 30.88 & 72 & 62.07 & \multirow{2}{*}{0.220} \\
\hline & Participated & 29 & 60.42 & 47 & 69.12 & 44 & 37.93 & \\
\hline
\end{tabular}

Source: Own survey result (2014). 
As shown in Table 3, the result indicated that there was statistically insignificant difference between the program participant and non-participant households regarding the sex of the household heads, the experience of utilizing chemical fertilizers and technology and participation of the household heads in credit service

Table 4. Descriptive statistics of sample households (for outcomes variables).

\begin{tabular}{|c|c|c|c|c|c|c|c|}
\hline \multirow{2}{*}{ Variable } & \multicolumn{2}{|c|}{ Treatment $(\mathrm{N}=4)$} & \multicolumn{2}{|c|}{ Control $(\mathrm{N}=68)$} & \multicolumn{2}{|c|}{ Total $(\mathrm{N}=116)$} & \multirow{2}{*}{ t-value } \\
\hline & Mean & Std. Err & Mean & Std. Err & Mean & Std. Err & \\
\hline CALI & 2131.94 & 138.65 & 1919.47 & 107.5 & 2006.97 & 85.41 & $4.85 * *$ \\
\hline PTLU & 2.15 & 0.21 & 2.16 & 0.20 & 2.15 & 0.14 & -1.23 \\
\hline HHFAM & 4882.1 & 338.56 & 1724.26 & 243.5 & 3030.9 & 246.3 & $5.3 * * *$ \\
\hline
\end{tabular}

${ }^{* * *}$ and ${ }^{* *}$ shows a level of significance at $1 \%$, and $5 \%$ respectively.

Source: Own econometric result (2014).

As shown above, in Table 4, the result showed that the average daily calorie intake of the whole sample households was 2006.97. The mean calorie intake of the program participant households and non-program participant households was found to be 2131.94 and 1919.47 kilocalories, respectively. Hence, the survey result showed that the program participant households were in a better status when compared to that of the non-program participant households in terms of daily calorie intake. The t-test result showed that there were statistically significant differences between the two groups at less than a $5 \%$ probability level (Table 4). The average livestock population owned by the total sample households was 2.154 in TLU. The average livestock population that was owned by the participant and non-participant households was 2.150 and 2.156 in terms of TLU, respectively. The result of this study showed that the mean difference of the livestock holding, in terms of TLU, between the program participant and non-participant households was statistically insignificant (Table 4). According to the result, those sample households that were participating in the program are almost the same as nonparticipant households in terms of livestock holding in the study area. In addition to this, the mean of farm and household material holding of participant and non-participant households was 4882.10 and 1724.26 ETB, respectively. This difference was statistically significant at less than $1 \%$ probability level. These results can tell us the household asset building has been improved as the difference in the mean value of farm and household material between the participant and non-participant households was positive and it was found to be statistically significant. According to the result, those sample households that were participating in the program are better off in terms of farm and household material holding in the study area.

\subsection{Propensity Score Estimation}

Estimation of the probability (propensity score) of each program participant and non-participant households as a function of observed household characteristics (Table 5). The study used eleven matching variables that were chosen as explanatory variables based on previous empirical studies and theories. Accordingly, only eleven relevant variables related to the intervention and outcome were considered in the propensity score function such as age, sex, educational level of household head, family size, size of cultivable land, household income in off/non-farm activities, distance to the nearest market, distance to nearest agricultural extension service, utilizing in chemical fertilizers and technology, dependency ratio and participation into credit service. In doing so, the dependent variable was a binary variable taking a value of 1 for household participation in PSNP or 0 otherwise.

Among these variables, the program participation decision is significantly influenced by four variables i.e. landholding size, off/non-farm income, distance to the nearest market, and distance to nearest agricultural extension offices were significantly affect the chance of being participant into the program and found to be statistically significant at different probability levels (Table 5). However, cultivable land owned and off/non-farm had a negative and significant effect on the PSNP participation decision. That means those households who have relatively larger landholding and those households who received income from off/non-farm income activities were less likely to be a participant in the program as expected and found to be statistically significant at less than $1 \%$ probability level.

Table 5. Participation Model Results of Estimated Propensity Score.

\begin{tabular}{|c|c|c|}
\hline Propensity Score Variables & Coefficients & $\mathbf{Z}$ \\
\hline SEX & $0.34(0.65)$ & 0.52 \\
\hline PAGE & $-0.00(0.02)$ & -0.18 \\
\hline PEDU & $-0.32(0.44)$ & -0.74 \\
\hline PFAMNO & $0.28(0.27)$ & 1.04 \\
\hline PLAND & $-2.71(1.09)$ & $-2.48 * * *$ \\
\hline HHOFFINCM & $-0.00(0.00)$ & $-3.99 * * *$ \\
\hline PMKTDIST & $0.47(0.25)$ & $1.86 *$ \\
\hline PAEXNSDIST & $0.42(0.22)$ & $1.91 * *$ \\
\hline PFERTKTECH & $0.79(0.75)$ & 1.06 \\
\hline ACCRDT & $-0.57(0.69)$ & -0.83 \\
\hline DEPRATIO & $0.01(0.58)$ & 0.02 \\
\hline Constant & $3.35(1.90)$ & $1.76^{*}$ \\
\hline Sample size & 116 & \\
\hline Wald chi ${ }^{2}(14)$ & 39.95 & \\
\hline Prob. $>$ chi $^{2}$ & 0.00 & \\
\hline Pseudo $\mathrm{R}^{2}$ & 0.52 & \\
\hline Log-likelihood & -37.47 & \\
\hline
\end{tabular}

${ }^{* * *},{ }^{* *}$ and ${ }^{*}$ show level of significance at $1 \%, 5 \%$ and $10 \%$ respectively.

Source: Own econometric result (2014). 
Once the propensity score estimation of the covariates has been estimated, the common support region should be imposed on the propensity score distributions of both sample groups. Importantly common support was improved by dropping treatment observations whose estimated propensity score is greater than the maximum or less than the minimum of the comparison group propensity scores. In the same manner, comparison group observations with a propensity score below the minimum or above the maximum of the treatment observations were also dropped (Figure 2).

Table 6. Distribution of estimated propensity scores.

\begin{tabular}{llllll}
\hline Group & N & Mean & Std. dev. & Max. \\
\hline Control & 68 & 0.12 & 0.23 & 0.95 & Min. \\
Treated & 48 & 0.83 & 0.22 & 0.00 & 1.00 \\
Total & 116 & 0.41 & 0.43 & 0.17 & 1.00 \\
\hline
\end{tabular}

Source: Own econometric result (2014).

As shown in Table 6 , the estimated propensity scores vary between 0.17 and 1.00 (mean=0.82) for program or treatment households and between 0.00 and 0.95 (mean=0.12) for nonprogram (control) households. The common support region would then lie between 0.17 and 0.95 . In other words, households whose estimated propensity scores are less than 0.17 and larger than 0.95 are not considered for the matching exercise. As a result of this restriction, 23 households (1 program and 22 control households) were discarded. This shows that the study does not have to drop many PSNP households from the sample in computing the impact estimator.

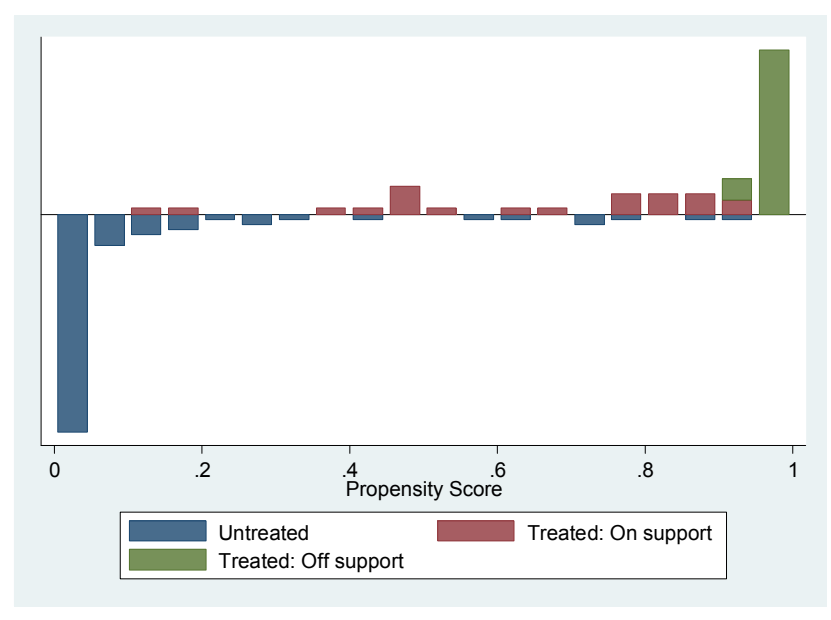

Figure 2. Schematic presentation of the common support condition.

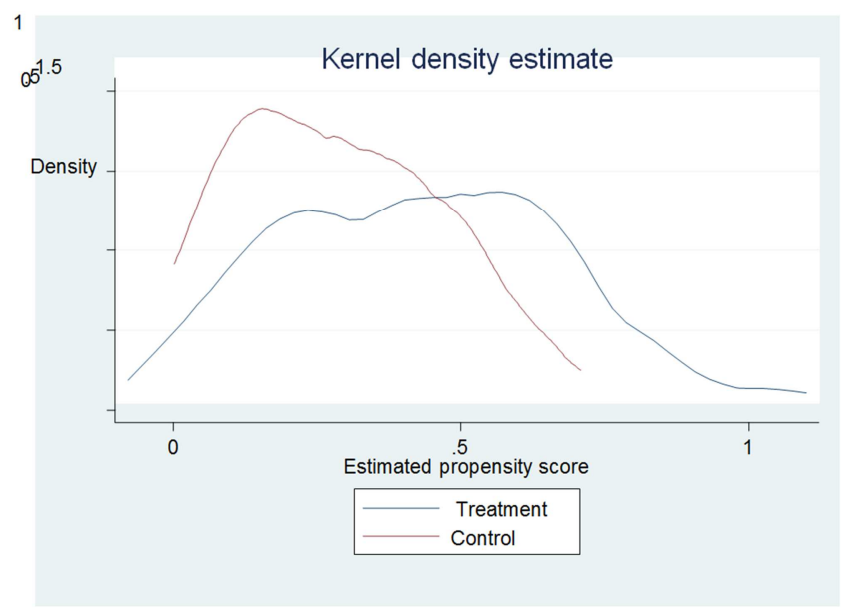

Figure 3. Kernel density of propensity scores.
Figure 2 portrays the distribution of the household with respect to estimated propensity scores. In the case of treatment households, most of them are found in the middle and the right side of the distribution. On the other hand, most of the control households are partly found in the center and more found on the left side of the distribution.

\subsection{Testing The Balance of Propensity Score and Covariates}

This was to perform a balancing test that tests the significance of the mean difference between all covariates used for the matching purpose before and after matching [1]. The objective of the balancing test is to verify that treatment is independent of unit characteristics after conditioning on observed characteristics (as estimated in the propensity score model), $\mathrm{D} \perp \mathrm{X} / \mathrm{P}(\mathrm{X})$ where $\mathrm{X}$ is the set of characteristics' that are believed to satisfy the conditional independence assumption. In other words, after conditioning on P (X) there should be no other variable that could be added to the conditioning set of the propensity score model that would improve the estimation and after the application of matching there should be no statistically significant differences between covariates mean of the treatment and comparison units. After matching tests, any difference in the covariates means between the two groups in the matched sampled has been eliminated because it should increase the likelihood of unbiased treatment effects.

After matching practices, any difference in the covariates means between the two groups in the matched sampled has been eliminated and therefore the pseudo- $\mathrm{R}^{2}$ should be fairly low [4]. The main purpose of the propensity score estimation is not to obtain a precise prediction of selection into treatment, but rather to balance the distributions of relevant variables in both groups. As shown in Table 7, obtaining the matching procedure technique resulted in the total bias reduction. According to Table 7, before matching, some variables were significantly different for the two groups of respondents i.e. sex, educational level of household heads, family size, distance to the nearest agricultural office, experienced with utilizing technology, participating in credit service and dependency ratio. But after matching these significant covariates were conditioned to be insignificant which indicates that the differences in covariates mean between the treated and control groups eliminated after 
matching and were balanced.

Table 7. Propensity score and covariates balancing.

\begin{tabular}{|c|c|c|c|c|c|c|}
\hline \multirow{2}{*}{ Variables } & \multirow{2}{*}{ Sample } & \multicolumn{2}{|l|}{ Mean } & \multirow{2}{*}{ Reduction bias\% } & \multicolumn{2}{|l|}{ Test } \\
\hline & & Treated & Control & & $\mathbf{T}$ & $\mathbf{p}>|\mathbf{t}|$ \\
\hline \multirow{2}{*}{ SEX } & Unmatched & 1.31 & 1.24 & \multirow{3}{*}{58.1} & $2.86^{* * *}$ & 0.00 \\
\hline & Matched & 1.33 & 1.07 & & 0.92 & \\
\hline \multirow{2}{*}{ PAGE } & Unmatched & 47.65 & 46.91 & & -0.39 & 0.69 \\
\hline & Matched & 48.36 & 49.30 & \multirow{2}{*}{-8.1} & -0.14 & \\
\hline \multirow{2}{*}{ PEDU } & Unmatched & 0.83 & 1.04 & & $3.14 * *$ & 0.00 \\
\hline & Matched & 0.86 & 0.36 & \multirow{2}{*}{66.9} & 1.08 & \\
\hline \multirow{2}{*}{ PFAMNO } & Unmatched & 4.65 & 4.26 & & $-4.61 * * *$ & 0.00 \\
\hline & Matched & 4.50 & 6.83 & \multirow[t]{2}{*}{-133.3} & -1.91 & \\
\hline \multirow{2}{*}{ PLAND } & Unmatched & 0.33 & 0.63 & & 0.99 & 0.32 \\
\hline & Matched & 0.37 & 0.32 & \multirow[t]{2}{*}{16.1} & 0.41 & \\
\hline \multirow{2}{*}{ HHOFFINCM } & Unmatched & 193.13 & 2032.31 & & -1.18 & 0.24 \\
\hline & Matched & 257.50 & 433.96 & \multirow[t]{2}{*}{-12.0} & -0.30 & \\
\hline \multirow{2}{*}{ PMKTDIST } & Unmatched & 2.27 & 4.06 & & -0.81 & 0.42 \\
\hline & Matched & 2.18 & 2.43 & \multirow[t]{2}{*}{-13.7} & -0.26 & \\
\hline \multirow{2}{*}{ PAEXSNSDIST } & Unmatched & 2.16 & 3.82 & & $-2.28 * *$ & 0.02 \\
\hline & Matched & 2.47 & 3.21 & \multirow[t]{2}{*}{-42.3} & -0.88 & \\
\hline \multirow{2}{*}{ PFERTKTECH } & Unmatched & 0.35 & 0.26 & & $-2.63 * * *$ & 0.01 \\
\hline & Matched & 0.31 & 0.60 & \multirow[t]{2}{*}{-64.4} & -1.34 & \\
\hline \multirow{2}{*}{ ACCRDT } & Unmatched & 0.60 & 0.69 & & $-2.09 * *$ & 0.04 \\
\hline & Matched & 0.50 & 0.74 & \multirow[t]{2}{*}{-49.0} & -0.76 & \multirow{3}{*}{0.08} \\
\hline \multirow{2}{*}{ DEPRATIO } & Unmatched & 0.93 & 0.66 & & $1.73 *$ & \\
\hline & Matched & 0.88 & 0.66 & 35 & 0.60 & \\
\hline
\end{tabular}

***,** and ${ }^{*}$ show level of significance at $1 \%, 5 \%$ and $10 \%$ a respectively.

Source: Own econometric result (2014).

\subsection{Estimating Treatment Effect On The Treated}

This section presents and discusses the results of the PSM technique to assess the impact of PSNP on household food security status. It explains the estimation of propensity scores, matching methods, common support region, balancing test of covariates, and sensitivity analysis. It also explains the treatment effect of the intervention across the participating households (program participants). To attain the main and the specific stated objectives of this study, this section evaluated the program's impacts on the outcome variable for their significant impact on participant households, after the pre-intervention differences were controlled. The specific impact indicator which was considered as outcome variable was daily calorie intake per adult equivalent (CALI).

Table 8. The average treatment effect on the treated.

\begin{tabular}{|c|c|c|c|c|c|}
\hline \multirow{2}{*}{$\begin{array}{l}\text { O Outcome } \\
\text { Variable }\end{array}$} & \multicolumn{2}{|l|}{ Mean } & \multirow{2}{*}{ ATT } & \multirow{2}{*}{ SE } & \multirow{2}{*}{ t-stat } \\
\hline & Treated & Control & & & \\
\hline CALI & 1824.66 & 1591.62 & 233.04 & 168.32 & $1.38^{*}$ \\
\hline
\end{tabular}

As above Table 8 showed that the program intervention has resulted in a positive and statistically significant mean difference between participant and non-participant household heads of the program's daily calorie intake. A positive value of ATT confirmed that food security and the household asset has been improved due to the PSNP program intervention in the study area.

After passing different steps of matching technique, it has been found out that the program intervention has increased daily calorie intake of the program participant households by 233.04 kilocalories. This difference was significant at a 5\% probability level respectively. This result can tell us the main objective of the PSNP, the household food security has been improved as the difference in the mean value of daily calorie intake between the participant and non-participant households was positive and it was found to be statistically significant.

\section{Conclusions and Recommendations}

This paper used a propensity score matching technique to analyze the impact of productive safety net program on the household food security status of households in the selected kebeles of Kutaber district. Propensity score matching has resulted in 47 participant households to be matched with 46 non-participant households. In other words, a matched comparison of calorie intake outcome was performed on these households who shared similar characteristics except the program. The resulting matches passed a variety of matching quality tests and were fit for answering the study's objectives. After controlling for other characteristics, it has been found that the PSNP has significantly raised calorie intake and farm and household materials of the program participant households by 233.04 kilocalories and 2551.65 ETB and this difference was significant at $10 \%$ and $5 \%$ probability level respectively in the study area. A positive value of ATT confirmed that the food security and the household asset have been improved due to the PSNP program intervention in the study area.

The analysis result shows that the household food security 
status of participants in PSNP is influenced by variables such as cultivable land units owned, off/non- farm income of the household head, distance from nearest agricultural extension agents' office and distance from the nearest market place. When comparing with non-participant households, program participants are found to be more likely to be food secured in the district. This finding is instinctively appealing since the program has been implemented in this area for more than 8 years.

Integrated productive safety net programs are important development efforts to improve the food security status of the household if it is implementing properly. Based on the empirical findings reported in this study, the following policy recommendations are forwarded concerning the enhancement of the food security capacity and status of the household in the study area.

1. In order to increase food production on the already available farmland owned by the participant households it is highly recommended that introduce modern farming systems with the increased use of modern farm management practices and inputs such as chemical fertilizers, pesticides, insecticides, and improved seeds. And the provision of special agricultural extension services and training for the participants as one component of other food security programs is also recommended to reduce program participants.

2. Currently, off/non-farm activities play a great role by bringing various income sources and are common practices of most of the rural households. In this regard, households who are engaged in such activities would be less likely to the participant and better endowed with additional income to meet their food and non-food requirements. So it is recommended that the concerned body should provide opportunities for the rural farm households to engage in income-generating off/nonfarm activities to enable the participant household to diversify their income sources, to meet their food and non-food requirements.

3. The proximity of the households' village to the nearest agricultural extension agents' office may have different opportunities to utilizing chemical fertilizers and different technologies that may increase their agricultural productivity. The study revealed that extension contact significantly affects and highly correlated with improving the food security status of the households. Therefore, it is recommended that the government and other concerned bodies who are working on similar jobs need to strengthen the services and to expand the locally existing extension service centers to disseminate and transfer appropriate agroecologically viable, improved farm implements, and introducing improved new technologies that can reduce the vulnerability of the participant households from recurrent food shortage.

4. In addition to this, access to the market center may create opportunities for more income by providing off/non-farm employment and easy access to transportation. Proximity to market centers creates access to additional income and improves their income by providing and selling different agricultural products, a better chance to reduce household poverty and participation in the program. So it is highly recommended that the concerned body should settle households around the existing market center and the newly opening markets in the study area. Further research using large sample size and in different locations should be conducted to gain more insight and precisions into the impact of PSNP on household food security. Parallel implementation of other productive food security programs within PSNP participants is highly recommended to improve the food security status of the households in the study area.

\section{References}

[1] ACF (2006), "The State of Food Security Policy and Programming in Ethiopia". ACF International Network, ACF Ethiopia, Addis Ababa.

[2] African Development Bank (2014), "Africa Food Security Brief: Special focus on climate Africa Food Security Change Impacts”. Statistics Department, Issue No 5, April 2014.

[3] Bernard, T., D. J. Spileman, Alemayehu Seyoum and Eleni Gabremadhin (2010), "Cooperatives for staple crop marketing". Evidence from Ethiopia. International Food Policy Research Institute (IFPRI) research monograph; 164.

[4] Caliendo, M. and S. Kopeinig (2005), "Some Practical Guidance for the Implementation of Propensity Score Matching”. Discussion Paper No. 1588, University of Cologne.

[5] Devereux, S. (2006), "Ethiopia's Productive Safety Net Program (PSNP): Trends in PSNP Transfers within Targeted Household).

[6] Devereux, S., Sussex, I. (2000a), "Food insecurity in Ethiopia, in: A DFID Ethiopia Seminar", London.

[7] EEA (2008), "Report on the Ethiopian Economy". Addis Ababa. Ethiopian Economic Association". No. Volume VI 2006/07.

[8] FAO (2010), "The state of food insecurity in the world: Addressing food insecurity in protracted crises". UNFAO. Rome, Italy.

[9] FDRE (2010), "Ethiopia's agricultural sector policy and investment framework 2010-2020”. Federal Democratic Republic of Ethiopia, Ministry of Agriculture and Rural Development. Draft final report, 15 September 2010.

[10] Feleke ST, Kilmer RL, Gladwin CH. (2005), "Determinants of food security in southern Ethiopia at the household level". Agric Econ 33 (3): 352-363.

[11] Gilligan, D. OJ, Hoddinott, and A. S. Taffesse (2008), “An analysis of ethiopia's productive safety net program and its linkages". Washington, Dc: International Food Policy Research Institute.

[12] GOV (200), "Ethiopia-The 2005 Humanitarian Requirements' Document. Joint Government and Humanitarian Partners' Document". 
[13] Heinrich, C., A. Maffioli and G. Vazquez (2010), “A primer for applying propensity score matching: impacts evaluation guidelines". University of Wisconsin-Madison, USA.

[14] IFPRI (2013), "Highlights of recent IFPRI food policy research for DFID”. Washington: IFPRI.

[15] Katane GO. (2013), "An assessment of the PSNP in selected kebeles of Konso Special Woreda, Southern Nations, Nationalities, and Peoples Regional State". In Food Security, Safety Nets and Social Protection in Ethiopia, Rahmato D, Pankhurst A, van Uffelen J-G (eds). Forum for Social Studies: Addis Ababa.

[16] KARDO (2014), "Kutaber Agricultural and Rural Development Office". Statistical bulletin. Unpublished document, Kutaber.

[17] KFEDO (2014), "Kutaber Finance and Economic Development Office". Statistical bulletin. Unpublished document, Kutaber.
[18] Little, P. D. (2008), "Food Aid Dependency in the North eastern Ethiopia". Myth or Reality? World Development, 36 (5): 860-874.

[19] Slater, R. Ashley, S., M. Tefera, M. Buta, and D. Esubalew (2006), "Ethiopia Productive Safety Net Programme (PSNP) PSNP Policy, Programme and Institutional Linkages". Overseas Development Institute, the IDL group, UK, and Indak International.

[20] Webb, P. and V. J Braun (1994), "Famine and Food Security in Ethiopia". (Lesson for Africa, England: John Wiley and Sons Ltd).

[21] WFP (2013), 'Fighting Hunger World Wide: Annual Report. Ethiopia".

[22] WFP and CSA (2014), "Comprehensive Food Security and Vulnerability Analysis in Ethiopia". Addis Ababa, Ethiopia.

[23] Yamane, T. (1967), "Statistics, An Introductory Analysis", (New York, 2nd Ed., Harper and Row). 